\title{
PERBEDAAN DUKUNGAN SOSIAL DARI IBU MERTUA PADA IBU MENYUSUI YANG BEKERJA DAN TIDAK BEKERJA
}

\author{
Ayu Rakhmi Pris Purnamasari, Rina Rahmatika \\ Fakultas Psikologi Universitas YARSI \\ Jalan Letjen Suprapto Cempaka Putih, Jakarta Pusat 10510 \\ ayurakhmi.prispurnamasari@gmail.com
}

\begin{abstract}
Mother in law also has role to support the success of exclusive breastfeeding, beside biological mother. This study aimed to investigate differences between perceived breastfeeding social support from mother-in-law on working and not working-women. There are 200 sample of this study, which is divided to 2 groups of 100 working-women and 100 not working-women. Perceived breastfeeding social support scale (27 item, $\alpha=.95)$ is used in this study and it is constructed by using social-functional support theory. Result shows that there is significant differences between perceived breastfeeding social support from mother in law on working and not working women $(\mathrm{t}(198)=2.42 ; \mathrm{p}=.016 ; p<.05)$. Emotional support and informational support from mother-inlaw more perceived by not working women than working mom, in the other hand, working women and not working women have no different perception about instrumental support. Result of this study may be one of information that can be used to inform mother-in-law about how precious social support is to exclusive breastfeeding.
\end{abstract}

Keywords: social support; mother-in-law; breastfeeding

\begin{abstract}
Abstrak
Peran ibu tidak hanya dimiliki oleh seorang ibu kandung, tetapi juga dimiliki oleh ibu mertua dalam mendukung keberhasilan program menyusui eksklusif. Penelitian ini bertujuan untuk melihat perbedaan dukungan sosial menyusui ibu mertua yang dipersepsikan oleh menantu bekerja dan tidak bekerja. Subjek penelitian berjumlah 200 ibu menyusui yang terbagi dalam 2 kelompok, yaitu ibu yang bekerja dan tidak bekerja. Penelitian ini menggunakan alat ukur skala dukungan sosial menyusui (27 item, $\alpha=0,95$ ) yang disusun oleh peneliti berdasarkan teori dukungan sosial fungsional. Penelitian ini menggunakan analisis uji-t. Penelitian ini menghasilkan t-hitung sebesar ( $(198)=2,42 ; \mathrm{p}=0,016 ; p<0,05)$. yang berarti bahwa terdapat perbedaan dukungan sosial dari ibu mertua pada ibu menyusui yang bekerja dan tidak bekerja. Hasil menunjukkan bahwa perempuan tidak bekerja lebih mempersepsikan adanya dukungan sosial menyusui dari ibu mertua dibandingkan dengan yang dipersepsikan oleh perempuan bekerja pada dimensi dukungan emosi dan dimensi dukungan informasi. Sedangkan, pada dukungan instrumental tidak ditemukan perbedaan dukungan sosial menyusui yang dipersepsikan oleh perempuan bekerja dan tidak bekerja. Hasil penelitian dapat menjadi salah satu acuan bagi ibu mertua yang memiliki menantu menyusui bekerja dan tidak bekera, yaitu untuk meningkatkan dukungan sosial menyusui sesuai dengan kebutuhan ibu menyusui agar kebutuhan gizi anak melalui pemberian ASI dapat terpenuhi dengan baik.
\end{abstract}

Kata Kunci: dukungan sosial; ibu mertua; menyusui.

\section{PENDAHULUAN}

Air Susu Ibu (ASI) tersusun atas kombinasi nutrisi unik yang memberikan manfaat bagi sistem imun pada tubuh manusia (Padovani, Duarte, Martinez, \& Linhares, 2011). Nutrisi pada ASI sampai saat ini belum ada yang dapat menyamakan atau bahkan menggantikan. Pada ASI terdapat kandungan protein dan laktosa tinggi yang dapat mempengaruhi pembentukan myelin pada otak yang dapat membantu perkembangan kognitif anak (Jedrychowski, Perera, Jankowski, 
Butscher, Mroz, Flak, Kaim, Miszczyk, Skarupa, \& Sowa, 2011). Sementara, durasi menyusui yang dilakukan seorang ibu dapat membantu prediksi kesehatan mental anak saat usia remaja. Manfaat pemberian ASI tidak hanya didapat oleh bayi tetapi juga oleh sang ibu, seperti: meminimalkan risiko pendarahan akibat kontraksi rahim, penurunan berat badan setelah melahirkan, dan sebagai solusi menunda kehamilan selama belum menemukan alat kontrasepsi yang tepat (Kementrian Kesehatan, 2013).

Manfaat dan keutamaan ASI yang begitu besar membuat banyak pihak memperhatikan pelaksanaan program ASI eksklusif. Saat ini, badan kesehatan dunia -the World Health Organization- telah merekomendasikan pemberian ASI eksklusif selama enam bulan dan meneruskannya hingga bayi berusia dua tahun (dalam Clifford \& Mclntyre, 2008). Hal tersebut ditegaskan kembali dengan penetapan PP nomor 33 tahun 2012 oleh pemerintah Indonesia yang terkait dengan kewajiban pemberian ASI eksklusif bagi ibu yang baru melahirkan (Kementrian Kesehatan, 2013).

Keberhasilan program menyusui eksklusif dipengaruhi oleh faktor internal dan faktor eksternal. Faktor internal terdiri dari persepsi, motivasi, ketekunan, dan stress. Sementara, faktor eksternal terdiri dari promosi yang gencar dan dukungan dari berbagai pihak (Rahmah, 2011). Faktor eksternal banyak berpengaruh pada budaya kolektif dan interdependen yang menekankan penyesuaian diri pada kelompok (Matsumoto, 2008). Studi yang dilakukan oleh Setiadi (dalam Geogras, Berry, Vijver, KağitÇibaşi, \& Poortingga, 2006) menggambarkan keluarga di Indonesia memiliki karakteristik interdependen. Pada keluarga inti tetap terdapat campur tangan pihak lain, seperti orang tua dan keluarga besar.
Pada budaya interdependen tersebut, orang tua, khususnya ibu yang akan ikut berpartisipasi dalam pengasuhan (Marx, Miller, \& Huffmon, 2011). Ibu yang telah menjadi seorang nenek memiliki peran untuk ikut mengawasi perkembangan dari cucu dengan memberikan nasihat yang sesuai dengan tradisi dan pendidikan agama (Setiadi dalam Geogras, dkk., 2006). Peran penting seorang ibu terdapat dalam pengambilan keputusan bagi anak, termasuk keputusan menyusui (Setiadi dalam Geogras, dkk., 2006). Peran tersebut terlihat ketika ibu menceritakan pengalaman saat mereka menyusui. Pengalaman positif dan negatif yang dialami ibu akan mempengaruhi keputusan tersebut. Selain itu, anak yang mendengar cerita negatif mengenai pengalaman ibunya saat menyusui cenderung lebih memilih menggunakan susu formula dibandingkan memberikan ASI (Grassley, Spencer, \& Law, 2012). Peran ibu berupa bantuan langsung tidak hanya didapat dari cerita pengalaman ibu tetapi juga dari pengetahuan yang terus berkembang mengenai ASI dan dapat diperoleh melalui diskusi, pelatihan, promosi kesehatan, dan seminar (Clifford \& Mclntyre, 2008 ; Grassley \& Eschiti, 2011; Grassley, Spencer, \& Law, 2012).

Peran ibu yang besar menjadi sebuah dukungan bagi perempuan yang sedang menyusui. Dukungan yang diberikan dapat mempengaruhi keputusan untuk menyusui dan durasi dari menyusui tersebut (Susin, Giugliani, \& Kummer, 2005; Shahla, Fahy, \& Kable, 2010). Susin, dkk (2005) dalam studi yang dilakukan menjelaskan bahwa ibu yang tidak berperan ketika anak perempuannya menyusui akan membuat durasi menyusui semakin cepat, yaitu sekitar empat bulan.

Perempuan yang telah menikah dan menjadi anggota baru dalam sebuah keluarga memiliki orang tua tambahan, 
yaitu ibu mertua dan ayah mertua. Pada proses menyesuaikan diri dalam pernikahan, adakalanya merasa terdapat perbedaan pendapat dan prinsip dari ibu mertua. Pendapat dan prinsip yang ada didasari oleh perbedaan kebiasaan dan budaya keluarga. Hal tersebut sering menjadi sumber konflik sehingga menantu tersebut lebih memilih untuk menghindar dari ibu mertua (Ririen, 2007).

Hubungan yang memburuk akibat munculnya konflik yang dialami antara ibu mertua dan menantu perempuan akan dapat mempengaruhi pemberian dukungan sosial (Ririen, 2007; Fitroh, 2011). Pengasuhan terhadap anak dapat menjadi potensi konflik antara ibu mertua dan menantu. Salah satunya karena ada rasa tidak yakin pada kemampuan menantu dalam mengurus anak, termasuk dalam memenuhi gizi anak dengan menyusui (Cotterill, 2005).

Ibu mertua akan membagi informasi dan pengalaman berupa masalah pada masa menyusui demi kecukupan gizi dari cucu yang disusui oleh menantunya (Grassley \& Eschiti, 2011). Ibu mertua dapat berbagi informasi dengan berbagai cara, misalkan bertemu langsung atau melalui media komunikasi lainnya (Cotterill, 2005; Marx, Miller, \& Huffmon, 2011).

Perempuan yang tidak bekerja memiliki waktu yang lebih banyak bersama dengan anaknya karena tidak terikat aktivitas ekonomi lain. Perempuan yang tidak bekerja akan memusatkan aktivitas di rumah dengan menjaga keluarga dan merawat anak (Ananda, 2013). Hal tersebut memungkinkan ibu mertua untuk lebih banyak berkomunikasi dengan menantu tidak bekerja dibandingkan dengan ibu mertua yang memiliki menantu bekerja (Cotterill, 2005). Pada akhirnya, ibu mertua mempercayakan pengasuhan anak termasuk menyusui secara eksklusif sepenuhnya pada menantu yang tidak bekerja.

Sementara itu, pada beberapa dekade terakhir banyak perempuan yang memiliki peran ganda, yaitu sebagai ibu rumah tangga dan wanita karier. Data Badan Pusat Statistik menunjukkan pada Februari tahun 2013 terdapat 1.751.800 perempuan yang bekerja di Jakarta (BPS, 2013). Studi yang dilakukan oleh Siregar (2007) dan Bakar (2012) menunjukkan bahwa perempuan yang bekerja memiliki peran ganda, yaitu sebagai ibu rumah tangga dan sebagai pekerja. Perempuan yang bekerja menggunakan sebagian waktunya untuk melakukan aktivitas selain mengurus rumah tangga, sementara menyusui memerlukan waktu rutin dalam pemberian ASI pada anak. Hal tersebut membuat perempuan yang bekerja mencari alternatif untuk tetap dapat memberikan ASI pada bayinya. Tuntutan komitmen dalam pekerjaan juga menjadi hambatan pada ibu menyusui yang bekerja karena perempuan yang bekerja mengalami konflik peran, yaitu peran sebagai ibu dan peran sebagai wanita bekerja (Müller \& Silva, 2009).

Pada kondisi tersebut ibu mertua akan membantu dalam pengasuhan, misalnya terlibat langsung dalam mengasuh dan menjaga cucu (Cotterill, 2005; Setiadi dalam Geogras, dkk., 2006). Ibu mertua dapat membantu menjaga cucu dan memberikan ASI yang telah diperah sebelumnya saat anak merasa haus atau lapar. Perbedaan kondisi pada perempuan bekerja dan tidak bekerja tersebut dapat berdampak pada keputusan untuk menyusui anak. Penelitian yang dilakukan oleh Ong, Yap, Li, dan Choo (2005) menunjukkan bahwa perempuan bekerja lebih cepat untuk berhenti menyusui dibandingkan dengan perempuan yang tidak bekerja. Alasan yang mendasari keputusan berhenti tersebut adalah terkait dengan pekerjaan. Perempuan bekerja 
membutuhkan pendampingan baik secara emosi maupun informasi terkait keberhasilan menyusui tanpa harus berhenti dari pekerjaan (Ong, dkk., 2005; Grassley \& Eschiti, 2008). Hal tersebut termasuk bentuk dukungan sosial yang diberikan oleh ibu mertua.

Perbedaan kondisi perempuan yang bekerja dan tidak bekerja dapat memunculkan respon yang berbeda, termasuk bagaimana dukungan sosial yang diberikan oleh ibu mertua yang dipersepsikan. Perbedaan dukungan sosial yang dipersepsikan muncul seiring dengan kebutuhan yang berbeda dari perempuan bekerja dan perempuan tidak bekerja. Kondisi pertama, tidak ada perbedaan yang signifikan pada kesehatan psikologis dari perempuan bekerja dan tidak bekerja, namun, perbedaan status kesehatan fisik dari perempuan yang bekerja dan tidak bekerja dapat terlihat jelas. Status kesehatan tersebut dipengaruhi oleh aktivitas perempuan bekerja yang dapat membuat kelelahan dan rentan terhadap sakit (Saravi, Navidian, Rigi, \& Montarezi, 2012). Kondisi ini dapat membuat ibu mertua yang memiliki menantu bekerja menyarankan untuk mengkonsumsi suplemen atau ramuan tradisional untuk mencukupi gizi selama masa menyusui dibandingkan dengan ibu mertua yang memiliki menantu tidak bekerja.

Selain itu, perempuan yang bekerja memiliki kecemasan yang lebih tinggi dibandingkan dengan perempuan yang tidak bekerja karena meninggalkan anak dalam beberapa waktu (Adhikari, 2012). Pada kondisi ini, ibu mertua dapat menenangkan, meyakinkan untuk dapat menyusui secara eksklusif, dan membelikan kebutuhan selama masa menyusui bagi menantu yang bekerja. Namun, kondisi lain pada menantu yang tidak bekerja yang belum tentu memiliki sumber stres selain masalah rumah tangga dan masalah sosial (Adhikari, 2012). Ibu mertua memberikan perhatian dalam bentuk yang lainnya, misalnya merekomendasikan tempat kebutuhan menyusui.

Kebutuhan nutrisi anak berusia di bawah 2 tahun lebih dapat dipantau dan dikontrol oleh perempuan yang tidak bekerja dibandingkan dengan perempuan yang bekerja (Shams, Golshiri, Saleki, Isfagani, \& Najimi, 2012). Ibu mertua dapat berperan dalam memberikan asupan ASI secara langsung selama perempuan bekerja dibandingkan dengan perempuan yang tidak bekerja. Sementara, perempuan yang tidak bekerja dapat secara langsung memberikan, memantau, dan mengontrol pemberian ASI pada anak tanpa harus mendapatkan bantuan tersebut dari ibu mertua.

Selain itu, kondisi menantu yang bekerja akan membuat intensitas pertemuan dengan ibu mertua menjadi berkurang. Menantu biasanya akan menemui ibu mertua setelah menyelesaikan pekerjaan atau saat berkunjung ke rumah ibu mertua yang termasuk dalam rutinitas (Cotterill, 2005). Kemungkinan untuk mengeluhkan hal-hal yang terkait dengan hambatan saat menyusui akan lebih bervariasi dan membuat ibu mertua lebih memperhatikan. Sementara, menantu yang tidak bekerja akan lebih banyak memiliki waktu yang dapat digunakan untuk bertemu ibu mertua dibandingkan dengan menantu yang bekerja.

Pengukuran dukungan sosial dikelompokkan menjadi dua berdasarkan social network, yaitu dukungan sosial yang diterima (received social support) dan dukungan sosial yang dipersepsikan (perceived social support). Dukungan sosial yang diterima mengidentifikasi presensi interaksi individu yang memiliki potensi untuk memberikan dukungan 
sosial. Pengukuran tersebut melihat partisipan yang spesifik, dan frekuensi kontak dengan individu. Sementara, dukungan sosial yang dipersepsikan mengidentifikasi hal-hal subjektif yang dirasakan oleh penerima dukungan sosial (Shor, Roelfs, \&, Yogev, 2013).

Hasil dari studi terlihat bahwa dukungan sosial yang dipersepsikan secara konsisten lebih menunjukkan efek positif dibandingkan dengan dukugan sosial yang diterima (Uchino, 2009; Shor, dkk., 2013). Selain itu, dukungan sosial yang dipersepsikan terbukti dapat memperpanjang rasa percaya pada ketersediaan dukungan dari lingkungan (Shor, dkk., 2013).

Dukungan sosial yang dipersepsikan memandang aktivitas sosial yang dirasakan atau dipersepsikan oleh penerimaaktivitas tersebut sebagai bentuk peningkatan penghargaan - atau apabila melibatkan bantuan antar individu yang terkait dengan stres (Heller, Swindle, \& Dusenbury, dalam Williams, 2005). Selain itu, dukungan sosial tidak hanya melihat faktor individual (kepribadian) tetapi juga faktor psikososial dan dapat difungsikan oleh atribut personal (Moreno, 2004; Uchino, 2009). Hal tersebut menjadi dasar dari konsep dukungan sosial yang dipersepsikan (Moreno, 2004).

Dukungan sosial yang dirasakan atau dipersepsikan (perceived support) merupakan penilaian yang melibatkan persepsi individu pada dukungan yang tersedia, kualitas dukungan tersebut, dan dukungan yang dibutuhkan oleh individu yang menilai (Weingarden \& Renshaw, 2014). Model dukungan sosial ini fokus kepada persepsi individu terhadap tersedianya dukungan dan pengukuran yang dilakukan berhubungan positif dengan kesehatan, seperti menurunkan stres serta meningkatkan kesehatan fisik dan mental (Williams, 2005; Nurullah, 2012).

Penelitian mengenai dukungan sosial menyusui telah banyak dilakukan, termasuk di Indonesia. Sebagian besar penelitian tersebut mengupas dukungan sosial menyusui yang diberikan oleh suami dan ibu. Dukungan menyusui dari suami dan ibu berupa pemberian keperluan menyusui, semangat, dan informasi yang terkait dengan menyusui. Dukungan sosial dari ibu sangat penting karena ibu memiliki pengalaman menyusui. Pengalaman yang pernah dialami oleh ibu menjadi informasi dan saran yang dapat meningkatkan intensi dan panjangnya durasi masa menyusui (Grassley \& Eschiti, 2011; Shahla, dkk., 2010).

Namun, belum mudah ditemukan penelitian yang mengupas secara langsung dukungan sosial menyusui ibu mertua (Susin, dkk., 2005; Williams, 2005; Clifford \& Mclntyre, 2008; Grassley \& Eschiti, 2008; Grassley \& Eschiti, 2011; Inayati, Scherbaum, Purwestri, Hormann, Wirawan, Suryantan, Hartono, Bloem, Pangaribuan, Biesalski, Hoffman, \& Bellows 2012). Padahal peran ibu tidak hanya dimiliki oleh seorang ibu kandung, tetapi juga dimiliki oleh ibu mertua (Cotterill, 2005; Inayati, dkk., 2012). Hal ini yang membuat peneliti tertarik untuk membuat penelitian yang bertujuan untuk mengetahui apakah terdapat perbedaan dukungan sosial ibu mertua yang dipersepsikan oleh menantu yang bekerja dan tidak bekerja pada masa menyusui.

Hipotesis dalam penelitian ini yaitu, terdapat perbedaan dukungan sosial ibu mertua, yang meliputi dukungan emosional, informasional, dan instrumental pada ibu bekerja dan tidak bekerja pada masa menyusui. 


\section{METODE}

Desain penelitian yang digunakan adalah studi komparasi non-eksperimental dengan membandingkan dua kelompok subjek yang memiliki karekteristik berbeda (Kumar, 1999). Teknik pengambilan sampel dalam penelitian ini menggunakan accidental sampling. Teknik accidental sampling adalah teknik penentuan sampel secara kebetulan, yakni siapapun yang bertemu dengan peneliti dapat digunakan sebagai sampel bila orang tersebut dipandang sesuai dan cocok sebagai sumber data (Sugiyono, 2011). Kriteria sampel yang digunakan pada penelitian ini, yaitu: ibu menyusui, usia anak yang disusui $0-6$ bulan, memiliki ibu mertua yang masih hidup, dan ditemui di wilayah Jabodetabek.

Penelitian ini mengukur satu variabel, yaitu dukungan sosial dari ibu mertua yang dipersepsikan oleh menantu yang menyusui. Dukungan sosial dari ibu mertua yang dipersepsikan oleh menantu adalah interaksi yang terjadi antara ibu mertua dan menantu yang memiliki hubungan formal dan informal melibatkan emosi, material, dan informasi serta dipersepsikan oleh menantu selama masa menyusui (Caplan dalam Littlewood, Swanke \& Strozier, 2013; House dalam Daalen, Sanders, Wilemsen, 2005). Dukungan sosial menyusui ibu mertua yang dipersepsikan menantu merupakan skor setiap dimensi yang diukur, yaitu dukungan emosi, dukungan informasi, dan dukungan instrumental dari ibu mertua yang dirasakan oleh subjek penelitian yang dapat mendukung keberhasilan masa menyusui. Variabel ini akan diukur pada dua kelompok subjek yang berbeda, yaitu kelompok perempuan berstatus menantu yang bekerja dan kelompok perempuan berstatus menantu yang tidak bekerja.

Sherbourne \& Stewart (1991) menjelaskan jenis dukungan sosial merupakan dimensi dari konsep dukungan sosial fungsional dan bersifat multidimensi. Dukungan sosial yang bersifat multidimensi ditandai dengan adanya tiga aspek (jenis) dukungan yang digunakan pada pengukuran penelitian tersebut (dalam Cohen, Underwood \& Gottlieb, 2000). Pada penelitian ini dimensi dukungan sosial yang digunakan adalah sebagai berikut:

1. Dukungan emosi, yaitu dukungan berupa mendengarkan secara aktif dan memberikan dorongan untuk tetap menyusui,

2. Dukungan informasi, yaitu dukungan berupa pemberian informasi, saran, dan nasihat terkait dengan menyusui,

3. Dukungan instrumental, yaitu dukungan berupa tindakan nyata, seperti finansial, pembelian alat bantuan program menyusui, atau peminjaman peralatan bantuan program menyusui.

Penelitian ini menggunakan alat ukur berupa skala psikologi yang dirancang oleh peneliti berbentuk skala Likert yang merujuk pada teori dukungan sosial yang dikemukakan oleh Helgeson \& Cohen (1996). Jumlah aitem dalam skala dukungan sosial menyusui terdiri dari 27 aitem $(\alpha=0,95)$. Terdiri dari 10 aitem ( $\alpha$ $=0,876$ ) dimensi dukungan emosi, 10 aitem ( $\alpha=0,861)$ dimensi dukungan informasi, dan 7 aitem $(\alpha=0,82)$ dukungan instrumental. Subjek penelitian ini diminta untuk memilih jawaban yang terdiri dari empat pilihan, yaitu "sangat sesuai", "sesuai", "tidak sesuai", dan "sangat tidak sesuai". Pernyataan sikap terdiri atas dua macam, yaitu favorable dan unfavorable. Pernyataan favorable merupakan pernyataan yang memiliki makna mendukung aspek perilaku dimensi yang diukur. Sementara, pernyataan unfavorable mengandung makna yang tidak mendukung aspek keperilakuan dari dimensi diukur (Azwar, 2012a). 
Penyebaran skala psikologi untuk mendapatkan data penelitian dilakukan kepada 300 responden di wilayah Jabodetabek yang sesuai dengan karakteristik penelitian ini dengan menggunakan teknik accidental sampling. Namun hanya 200 responden yang sesuai dengan karakteristik penelitian ini, yaitu $100 \mathrm{ibu}$ menyusui yang bekerja dan 100 ibu menyusui yang tidak bekerja. Hipotesis penelitian diuji dengan menggunakan uji statistik parametrik, yaitu uji-t. Data dalam penelitian ini diolah dengan menggunakan SPSS 16.0 for Windows.

Data demografi dari responden penelitian menunjukkan data yaitu sebanyak 83 orang berusia 23 - 26 tahun (42\%) dengan rincian 34 orang merupakan perempuan tidak bekerja dan 49 orang merupakan perempuan bekerja. Sebagian besar orang memiliki ibu mertua yang berdomisili di wilayah Jabodetabek (131 orang; 65,5\%) dan 23 orang $(11,5 \%)$ memiliki ibu mertua yang tinggal serumah dengan mereka. Latar belakang pendidikan orang didominasi oleh berpendidikan tinggi (program diploma/akademi, S1, S2, dan keprofesian), yaitu sebanyak 149 orang $(74,5 \%)$. Penelitian ini dilakukan pada dua kelompok, yaitu perempuan menyusui yang bekerja dan perempuan menyusui yang tidak bekerja, dengan perbandingan jumlah responden yaitu $100 \mathrm{ibu}$ menyusui yang bekerja dan 100 ibu menyusui yang tidak bekerja. Pada kelompok perempuan menyusui yang bekerja, sebanyak 57 orang $(28,5 \%)$ merupakan pegawai swasta. Mayoritas dari orang penelitian ini merupakan perempuan yang baru menjadi ibu atau baru memiliki satu anak, yaitu sebanyak 128 orang (64\%), dan 100 orang $(50 \%)$ di antaranya memiliki anak yang disusui berusia $3-5$ bulan. Sebanyak 128 orang $(64 \%)$ memutuskan target menyusui selama lebih dari 1,5 tahun.

\section{HASIL DAN PEMBAHASAN}

Dukungan sosial secara keseluruhan memilki nilai $\mathrm{t}(198)=2,42 ; \mathrm{p}<0,05$. Hal tersebut dapat diartikan Ha pada penelitian ini diterima dan Ho ditolak, terdapat perbedaan dukungan sosial menyusui dari ibu mertua yang dipersepsikan oleh menantu bekerja dan tidak bekerja. Pengujian ini menunjukkan perempuan tidak bekerja $(\mathrm{M}=73,08 ; \mathrm{SD}=10,55)$ merasakan dukungan sosial ibu mertua yang lebih tinggi dibandingkan dengan ibu bekerja $(\mathrm{M}=69,19 ; \mathrm{SD}=12,12)$.

Pengujian hipotesis pada dimensi dukungan emosi memiliki nilai $\mathrm{t}(198)=$ 2,15; $\mathrm{p}<0,05$. Hal tersebut dapat diartikan Ha diterima dan Ho ditolak, terdapat perbedaan dukungan emosi menyusui dari ibu mertua yang dipersepsikan oleh menantu bekerja dan tidak bekerja. Pengujian ini menunjukkan perempuan tidak bekerja $(\mathrm{M}=27,43 ; \mathrm{SD}=$ 3,85) lebih mempersepsikan dukungan emosi menyusui dari ibu mertua dibandingkan dengan perempuan bekerja $(M=26,12 ; S D=4,17)$. Dukungan emosi berupa empati, pemberian semangat, perhatian, dan rasa peduli dapat diperoleh selama masa menyusui dari ibu mertua (Kim \& Kovach, 2001; Williams, 2005; Shahla, dkk., 2010). Terkadang pada kultur kolektivistik, perempuan akan berhati-hati dalam membawa permasalahan menyusui kepada ibu mertua karena khawatir akan membebani (Kim, Sherman \& Taylor, 2008). Namun, ibu mertua yang juga berperan sebagai orang tua memfasilitasi kebutuhan dari menantu yang sedang menyusui karena adanya rasa peduli dan rasa tanggung jawab terhadap keluarga (Cotterill, 2005; Crocker \& Canevello, 2008; Kim, Sherman \& Taylor, 2008).

Pada proses pengumpulan data, peneliti mengalami kendala dalam menemukan 
subjek yang sesuai dengan karakteristik penelitian sehingga jumlah yang didapatkan pada tiap kelompok tidak seimbang. Hal yang dilakukan selanjutnya adalah memilih secara acak agar tiap kelompok memiliki jumlah yang seimbang. Jumlah subjek pada penelitian ini pada akhirnya berdasarkan rekomendasi Crocker \& Algina (dalam Azwar, 2012b) untuk memenuhi syarat cukup memadai, yaitu berjumlah 200 responden. Kemudian, dari jumlah tersebut dibagi menjadi dua kelompok, masing-masing kelompok berjumlah 100 responden.

Pada penelitian ini sebagian besar subjek memiliki target menyusui hingga lebih dari 1,5 tahun, yaitu 128 dari 200 orang (55 perempuan menyusui tidak bekerja dan 73 perempuan menyusui yang bekerja). Target tersebut dapat dipengaruhi oleh dukungan sosial yang diberikan berbagai pihak, termasuk dari ibu mertua. Dukungan sosial menyusui ibu mertua yang dipersepsikan oleh menantu kemudian diuji kepada dua kelompok untuk melihat perbedaannya, yaitu menantu yang tidak bekerja dan menantu yang bekerja.

Kebutuhan perempuan menyusui akan informasi-informasi yang terkait dengan menyusui dapat diperoleh dari ibu mertua melalui cerita menyusui yang pernah dilalui oleh ibu mertua (Grassley \& Eschiti, 2008). Hasil penelitian yang didapatkan menunjukkan dimensi dukungan informasi memiliki nilai $\mathrm{t}(198)$ $=2,46 ; \mathrm{p}<0,05$. Hal tersebut dapat diartikan terdapat perbedaan dukungan informasi menyusui dari ibu mertua yang dipersepsikan oleh menantu bekerja dan tidak bekerja. Pengujian ini menunjukkan perempuan tidak bekerja $(\mathrm{M}=27,46 ; \mathrm{SD}=$ 4,4) lebih mempersepsikan dukungan informasi menyusui dari ibu mertua dibandingkan dengan perempuan bekerja $(\mathrm{M}=25,81 ; \mathrm{SD}=5,04)$. Pemberian informasi mengenai menyusui dari ibu meliputi: pengalaman ibu mertua ketika dalam proses menyusui anak, hambatan saat menyusui, dan tips yang harus dilakukan (Grassley \& Eschiti, 2011). Berbagi pengalaman dan pengetahuan yang tepat (bukan sekadar mitos) mengenai menyusui menjadi salah satu dukungan yang dibutuhkan oleh perempuan yang sedang menyusui (Grassley \& Eschiti, 2008; Grassley \& Eschiti, 2011).

Kualitas dukungan sosial menyusui dapat dipengaruhi oleh kuantitas dan kualitas hubungan dengan ibu mertua (Rini, Scheter, Hobel, Glynn \& Sandman, 2006); Grassley \& Eschiti, 2008). Menantu bekerja dapat membuat intensitas pertemuan dengan ibu mertua menjadi berkurang sehingga baru dapat menemui ibu mertua setelah menyelesaikan pekerjaan atau saat berkunjung ke rumah ibu mertua secara rutin (Cotterill, 2005). Kondisi tersebut memungkinkan perempuan tidak bekerja memiliki waktu bersama dengan ibu mertua lebih banyak dari perempuan yang bekerja mendapatkan dukungan sosial menyusui. Kuantitas dari kebersamaan ibu mertua dengan menantu juga dapat dilihat dari domisili keduanya. Penelitian ini menelusuri domisili dari ibu kandung dan ibu mertua yang kemungkinan dapat mempengaruhi dukungan sosial menyusui. Namun, faktor domisili tidak dapat dibahas secara mendalam karena informasi mengenai domisili tidak dilakukan dengan detail (apakah subjek tinggal bersama atau tinggal terpisah dari ibu kandung maupun ibu mertua) dan hanya melihat domisili dari ibu mertua maupun ibu kandung subjek berada di wilayah yang sama (JABODETABEK) atau di luar wilayah tersebut. Hanya sebagian subjek yang menjelaskan tinggal bersama dengan ibu kandung/ibu mertua atau tinggal secara terpisah. 
Jumlah subjek yang berdomisili sama dengan ibu mertua berada pada kisaran yang sama, yaitu sebanyak 65 perempuan menyusui yang tidak bekerja dan sebanyak 66 perempuan menyusui yang bekerja. Hal tersebut memungkinkan mempengaruhi hasil penelitian ini terkait dengan kontak sosial dengan ibu mertua meskipun perbedaan jumlahnya tidak terlalu besar (Nurullah, 2012). Penelitian ini juga hanya melihat domisili dari ibu kandung yang diasumsikan dapat mempengaruhi dukungan sosial ibu mertua yang dipersepsikan oleh menantu. Domisili yang sama dengan ibu mertua memungkinkan menantu memiliki frekuensi pertemuan yang lebih besar dengan ibu mertua yang secara tidak langsung mempengaruhi dukungan sosial menyusui (Grassley \& Eschiti, 2008).

Dukungan sosial tidak hanya diberikan melalui perhatian dan berbagi informasi, tetapi juga dengan tindakan langsung atau pemberian yang melibatkan materi (Kim \& Kovach, 2001). Dukungan berupa tindakan atau pemberian barang termasuk ke dalam dimensi dukungan instrumental. Pengujian hipotesis pada dimensi dukungan instrumental menunjukkan nilai $\mathrm{t}(198)=$ 1,$92 ; \mathrm{p}>0,05 ; \mathrm{d}=0,35$. Hal tersebut dapat diartikan $\mathrm{Ho}$ diterima dan $\mathrm{Ha}$ ditolak, tidak terdapat perbedaan dukungan instrumental menyusui dari ibu mertua yang dipersepsikan oleh menantu bekerja dan tidak bekerja. Pengujian ini menunjukkan perempuan tidak bekerja (M $=18,19 ; \mathrm{SD}=3,33)$ dan perempuan bekerja $(M=17,26 ; \mathrm{SD}=3,52)$ tidak berbeda dalam mempersepsikan dukungan instrumental menyusui dari ibu mertua. Fischer (dalam Cotterill, 2005) menjelaskan bahwa perempuan butuh dan menerima bantuan lebih dari lingkungannya baik dalam bantuan personal, keuangan, dan pemberian barang. Kemudahan akses informasi yang berkaitan dengan perlengkapan menyusui dapat membantu perempuan menyusui mendapatkan hal yang dibutuhkan dan mempengaruhi dukungan instrumental yang dipersepsikan ibu mertua. Selain itu, salah satu peran suami dalam rumah tangga adalah memberikan nafkah materi dapat mempengaruhi perempuan dalam mempersepsikan dukungan instrumental menyusui dari ibu mertua (Rini, dkk., 2006; Clifford \& Mclntyre, 2008). Suami memenuhi kebutuhan materi isteri selama masa menyusui berupa memberikan perlengkapan menyusui dan membantu proses menyusui pada waktu-waktu tertentu, misalkan malam hari. Fenomena menggunakan asisten rumah tangga sebagai pengasuh tambahan juga dapat membuat ibu mertua tidak banyak terjun langsung untuk mengasuh cucu. Namun, penelitian ini tidak menggali apakah subjek menggunakan asisten rumah tangga untuk membantu mengasuh anak.

Dukungan sosial dipengaruhi oleh berbagai faktor, yaitu budaya, kedekatan emosional, keintiman, kelekatan, kualitas hubungan interpersonal, managemen konflik, orientasi network, dan social skill (Rini, dkk., 2006; Crocker \& Canevello, 2008; Kim, Sherman, \& Taylor, 2008). Dukungan sosial juga dipengaruhi oleh ketepatan waktu dalam proses pemberiannya (Pierce, Sarason \& Sarason, 1996). Dukungan sosial menyusui akan dirasakan ketika ibu mertua memberikannya menjelang persalinan dan masa menyusui dimulai (Grassley \& Eschiti, 2008). Ketika dukungan sosial menyusui diberikan pada waktu yang terlalu dini (misalkan pada awal kehamilan) atau bahkan saat semua kebutuhan menantunya telah terpenuhi maka hal tersebut dapat mempengaruhi dukungan sosial yang dipersepsikan. Dukungan sosial menyusui sangat diperlukan terutama ketika perempuan baru menjadi seorang ibu. Sebagian besar subjek pada penelitian ini merupakan 
perempuan yang baru menjadi ibu karena baru memiliki satu anak, yaitu sebanyak 128 orang.

Ibu mertua dapat berbagi pengalaman dan pengetahuan seputar menyusui kepada menantunya yang bergantung pada kemampuan mengingat peristiwa (Pierce, Lakey, Sarason \& Sarason, 1997; Cohen, dkk., 2000). Pengalaman yang dimaksud berupa pengalaman terdahulu ibu mertua saat menyusui. Penelusuran mengenai apakah ibu mertua menyusui secara eksklusif, bekerja, atau tidak bekerja dapat mempengaruhi isi dari berbagi pengalaman juga diperlukan pada penelitian mengenai dukungan sosial menyusui (Grassley \& Eschiti, 2011). Namun, hal tersebut tidak dilakukan dalam penelitian ini sehingga menjadi kekurangan penelitian ini.

Terdapat hal menarik yang ditemukan, yaitu satu subjek yang tidak bekerja dan satu subjek yang bekerja tinggal bersama dengan ibu mertua berserta ibu kandung. Perempuan bekerja tersebut lebih mempersepsikan dukungan sosial menyusui dari ibu mertua dibandingkan dengan perempuan tidak bekerja. Hal tersebut dapat dilihat dari kategori dukungan sosial yang dipersepsikan. Skor dukungan sosial menyusui ibu mertua yang dipersepsikan perempuan bekerja tersebut berada pada kategori tinggi. Sementara, skor dukungan sosial menyusui ibu mertua yang dipersepsikan perempuan tidak bekerja tersebut berada pada kategori sedang.

Penelitian ini juga menggali apakah yang subjek ketahui mengenai ASI dan menyusui eksklusif. Subjek diberikan 9 pernyataan dan 5 di antaranya merupakan pernyataan yang mengecoh. Enam dari 200 (3\%) subjek terkecoh menjawab ASI yang encer berkualitas buruk, 68 dari 200 (34\%) subjek terkecoh menjawab ASI mudah terkontaminasi, 129 dari 200
$(64,5 \%)$ subjek terkecoh menjawab periode menyusui secara eksklusif, 8 dari 200 (4\%) subjek terkecoh menjawab perlu adanya peningkatan gizi melalui asupan tambahan pada periode menyusui eksklusif, dan 14 dari 200 (7\%) subjek terkecoh menjawab perlu adanya bantuan susu formula jika ASI belum/tidak lancar di hari-hari pertama melahirkan. Jawaban subjek pada pertanyaan seputar ASI dan menyusui eksklusif tersebut tidak dapat dijadikan dasar mengevaluasi pengetahuan subjek penelitian karena pernyataan yang diberikan hanya seputar pengetahuan umum mengenai ASI dan menyusui eksklusif. Namun, hasil dari menjawab pernyataan tersebut dapat dijadikan fenomena baru mengenai gambaran umum ibu menyusui dalam mengenal ASI dan menyusui eksklusif. Sejalan dengan penelitian yang dilakukan oleh Grassley \& Eschiti (2007) yang menjelaskan perempuan membutuhkan advokasi dari ibu kandung dan ibu mertua selama masa menyusui. Advokasi yang diberikan berdasarkan fakta mengenai menyusui sehingga perlu dilakukan peningkatan pengetahuan bagi ibu mertua sejak menantu masih mengandung (Grassley \& Eschiti, 2011).

Selain itu, latar belakang pendidikan subjek pada penelitian ini memiliki interaksi dengan dukungan informasi, yaitu dengan nilai rata-rata perbedaan sebesar 3,38 pada subjek yang berpendidikan menengah dan subjek yang berpendidikan tinggi. Subjek yang berpendidikan menengah lebih mempersepsikan dukungan informasi yang diberikan oleh ibu mertua. Hal ini dapat disebabkan oleh subjek yang berpendidikan tinggi mendapatkan lebih banyak akses informasi menyusui yang lebih banyak sehingga kurang dapat mempersepsikan dukungan informasi menyusui yang diberikan oleh ibu mertua. Dukungan informasi menyusui dari berbagai sumber sebenarnya 
diperlukan agar program menyusui dapat dilakukan secara tepat. Pemberian informasi menyusui dapat dilakukan dengan berbagai cara, yaitu melalui: artikel pada media cetak maupun online, seminar, dan workshop.

Berdasarkan pada kelemahan penelitian ini terkait kedalaman informasi umum dari subjek yang dapat mempengaruhi pengukuran dukungan sosial menyusui. Pada penelitian selanjutnya dapat mengulas lebih dalam mengenai domisili baik ibu kandung maupun ibu mertua subjek, pengalaman menyusui terdahulu dari ibu mertua (sumber dukungan sosial menyusui), dan penggunaan jasa asisten rumah tangga. Berdasarkan beberapa kendala yang ditemui peneliti saat menentukan populasi dan jumlah sampel penelitian, peneliti menyarankan kepada pihak terkait dalam pendataan kependudukan untuk memberikan data kependudukan yang berada di wilayah Jabodetabek.

Hasil penelitian ini yang menunjukkan bahwa perempuan bekerja lebih mempersepsikan dukungan sosial menyusui dari ibu mertua dibandingkan dengan perempuan yang tidak bekerja. Perempuan bekerja dan tidak bekerja memiliki kondisi yang berbeda yang berdampak pada keputusan menyusui. Pada penelitian yang dilakukan oleh Ong, Yap, Li, dan Choo (2005) menunjukkan bahwa perempuan bekerja lebih cepat untuk berhenti menyusui dibandingkan dengan perempuan yang tidak bekerja. Alasan yang mendasari keputusan berhenti tersebut adalah terkait dengan pekerjaan. Hal tersebut menandakan bahwa perempuan bekerja membutuhkan pendampingan baik secara emosi maupun informasi terkait keberhasilan menyusui tanpa harus berhenti dari pekerjaan. Oleh karena itu, ibu mertua perlu meningkatkan dukungan sosial menyusui sesuai dengan kebutuhan, baik bagi menantunya yang bekerja dan tidak bekerja selama masa menyusui. Hal ini penting dilakukan agar kebutuhan gizi dari anak yang baru dilahirkan dapat terpenuhi dari pemberian ASI.

\section{KESIMPULAN}

Hasil yang diperoleh setelah melakukan analisis menunjukkan bahwa terdapat perbedaan dukungan sosial ibu mertua pada ibu menyusui yang bekerja dan tidak bekerja. Ditinjau dari dimensi dukungan emosi menyusui menunjukkan terdapat perbedaan dukungan sosial menyusui ibu mertua yang dipersepsikan oleh menantu yang bekerja dan tidak bekerja. Pada dimensi dukungan informasi menyusui menunjukkan terdapat perbedaan dukungan sosial menyusui ibu mertua yang dipersepsikan oleh menantu yang bekerja dan tidak bekerja. Pada dimensi dukungan instrumental menyusui menunjukkan tidak ada perbedaan dukungan sosial menyusui ibu mertua yang dipersepsikan oleh menantu yang bekerja dan tidak bekerja.

\section{DAFTAR PUSTAKA}

Ananda, M. R. (2013). Self-esteem antara ibu rumah tangga yang bekerja dengan yang tidak bekerja. Jurnal Online Psikologi. 1 (1).

Adhikari, H. (2012). Anxiety and depression: Comparative study between working and non-working mothers. Global Journal of Human Social Science Sociology, Economics, \& Political Science, 12 (12), 1-7.

Azwar, S. (2012a). Penyusunan skala psikologi. Edisi 2. Yogyakarta: Pustaka Pelajar.

Azwar, S. (2012b). Reliabilias dan validitas, edisi 4. Yogyakarta: Pustaka Pelajar. 
Bakar, N. R. A. (2012). Malaysian women in management. Journal of Society and Space, 8(4), 12-20.

BPS. (2013). Data penduduk bekerja di Jakarta. Diakses melalui https://jakarta.bps.go.id/

Cotterill, P. (2005). Friendly relations? Mothers and daughters-in-law. Bristol: Taylor and Francis eLibrary.

Cohen, S., Underwood, L. W., \& Gottlieb, B. H. (2000). Social support measurement and intervention. A guide for health and social scientists. New York: Oxford University Press, Inc.

Clifford, J., \& Mclntyre, E. (2008). Who supports breastfeeding?. Breastfeeding review, 16(2), 9-19.

Crocker, J. \& Canevello, A. (2008). Creating and undermining social support in communal relationship: The role of compassionate and selfimage goals. Journal of Personality and Social Psychology, 95(3), 555575. http://dx.doi.org/10.1037/00 22-3514.95.3.555

Daalen, G. V., Sanders, K., \& Wilemsen, T. M. (2005). Source of social support as predictors of health, psychological well-being and life satisfaction among Dutch male and female dual-earners. Journal of Women and Health, 41(2).43-62. http://dx.doi.org/10.1300/J013v41n 02_04

Fitroh, S. F. (2011). Hubungan antara kematangan emosi dan hardiness dengan penyesuaian diri menantu perempuan yang tinggal di rumah ibu mertua. PSIKOISLAMIKA Jurnal Psikologi Islam, 8(1), 83-98.

Grassley, J. S., \& Eschiti, V. (2007). Two generations learning together: facilitating grandmothers support of breastfeeding. International Journal of Childbirth Education, 22(3), 23-26.

Grassley, J. S., \& Eschiti, V. (2008). Grandmother breastfeeding support: What do mothers need and want?. Journal Compilation BIRTH, 35(4), 329-335. http://dx.doi.org.10.1111/j.1523536X.2008.00260.x

Grassley, J. S., \& Eschiti, V. (2011). The value of listening to grandmothers' infant-feeding stories. The Journal of Perinatal Education, 20(3), 134141. http://dx.doi.org/10.1891/1058 -1243.20 .3 .134 .

Grassley, J. S., Spencer, B. S., \& Law, B. (2012). A grandmothers' tea: Evaluation of a breastfeeding support intervention. The Journal of Perinatal Education, 21(2), 8089. http://dx.doi.org/10.1891/10581243.21.2.80

Geogras, J., Berry, J. W., Vijver, F. J. R. V. D., KağitÇibaşi, Ç., \& Poortingga, Y. H. (2006). Families across cultures a 30 nation psychological study. New York: Cambridge University Press.

Sherbourne, C. D., \& Stewart, A. L. (1991). The MOS social support survey. Social Science and Medicine, 32(6), 705-714. http://dx.doi.org/10.1016/02779536(91)90150-B. 
Helgeson, V. S., \& Cohen, S. (1996). Social support and adjustment to cancer: Reconciling descriptive, correlational, and interventional research. Health Psychology, 15(2), 135-148. http://dx.doi.org/10.1037/ 0278-6133.15.2.135.

Inayati, D. A., Scherbaum, V., Purwesti, R. C., Hormann, E., Wirawan, N. N., Suryantan, J., Hartono, S., Bloem, M. A., Pangaribuan, R. V., Biesalski, H. K., Hoffman, V., \& Bellows, A.C. (2012). Infant feeding practices among mildly wasted children: A retrospective study in Nias island, Indonesia. International Breastfeeding Journal, 7(3), 1-9. http://dx.doi. org/10.1186/17464358-7-3

Jedrychowski, W., Perera, F., Jankowski, J., Butscher, M., Mroz, E., Flak, E., Kaim, I., Lisowska-Miszczyk, I., Skarupa, A., \& Sowa, A. (2011). Effect of exclusive breastfeeding on the development of children's cognitive function in the Krakow prospective birth cohort study. European Journal of Pediatrics, 171(1), 151-168. http://dx.doi.org/10.1007/s00431011-1507-5.

Kementrian Kesehatan. (2013) ASI eksklusif bayi cerdas, ibu sehat. diakses melalui depkes.go.id pada tanggal 30 September 2013.

Kim, H., \& Kovach, A. C. (2001). Information and social support regarding breastfeeding: A survey of mothers in Seoul, South Korea. Journal of Korean Academy of Nursing, 31(7), pp.1151-1159.
Kim, H. S., Sherman, D. K., \& Taylor, S. E. (2008). Culture and social support. American Psychological Association, $63,318-326$. http://dx.doi.org/10.1037/0003066X

Kumar, R. (1999). Research methodology a step-by-step guide for beginners. Kuala Lumpur: SAGE Publications.

Littlewood, K., Swanke, J. R., \& Strozier, A. (2013). Measuring social support among Kinship caregivers: Validity and reliability of the family support scale. Child Welfare, 91(6), 59-78.

Marx, J., Miller, L. Q., \& Huffmon, S. (2011). Excluding mothers-in law: a research note on the preference for matrilineal advice. Journal of Family Issue, 32(9) 1205 - 1222. http://dx.doi.org/10.1177/0192513 X11402176.

Matsumoto, D. (2008). Pengantar psikologi lintas budaya. Yogyakarta: Pustaka Belajar.

Moreno, E. S. (2004). Colletivize social support? Elements for reconsidering the social dimension in the study of social support. The Spanish Journal of Psychology, 7(2), 124-134.

Müller, F. S., \& Silva, I. A. (2009). Social representations about support for breastfeeding in a group of breastfeeding women. Rev. Latinoam Enfermagem, 17(5), 651-657. http://dx.doi.org/10.1590/S010411692009000500009.

Nurullah, A. S. (2012). Received and provided social support: a review 
of current evidence and future directions. American Journal of Health Studies, 27(3), 173-188.

Ong, G., Yap, M., Li, F. L., \& Choo, T. B. (2005). Impact of working status on breastfeeding in Singapore evidence from the national breastfeeding survey 2001. Europan Journal of Public Health, 15(4), 424 - 430. http://dx.doi.org /10.1093/eurpub/cki030

Padovani, F. H. P., Duarte, G., Martinez, F. E., \& Linhares, M. B. M. (2011). Perceptions of breastfeeding in mothers of babies born preterm in comparison to mothers of full-term babies. The Spainish Journal of Psychology, 14(2), 884-898. http://dx.doi.org/10.5209/

Rahmah, L. (2011). Atribusi tentang kegagalan pemberian asi pada ibu pekerja (sebuah studi fenomenologi). Jurnal Proyeksi, 6, $62-70$.

Rini, C., Scheter, C. D., Hobel, C. J., Glynn, L. M., \& Sandman, C. A. (2006). Effective social support: Antecedences and consequence of partner support during pregnancy. Journal of Personal Relationship, 13, $207 \quad-\quad 229$. http://dx.doi.org/10.1111/j.14756811.2006.00114.x

Ririen. (2007). Hubungan antara komunikasi interpersonal dengan penyesuaian diri menantu perempuan terhadap ibu mertua. Skripsi. Salatiga: Fakultas Psikologi Universitas Katolik Soegijapranata.

Pierce, G. R., Sarason, B. R., \& Sarason, I. G. (Eds.). (1996). Handbook of social support and the family. New York: Plenum Press. http://dx.doi.org/10.1007/978-14899-1388-3

Pierce, G. R., Lakey, B., Sarason, B. R., \& Sarason, I. G. (1997). Sourcebook of social support and personality. New York: Plenum Press. http://dx.doi.org/10.1007/978-14899-1843-7

Saravi, F. K., Navidian, A., Rigi, S. N., \& Montazeri, A. (2012). Comparing health-related quality of life of employed women and housewifes: A cross sectional study from shoutheast Iran. Journal BMC Women's Health, 12(41), 1-5.

Shahla, M., Fahy, K., \& Kable, A. K. (2010). Factors that positively influence breastfeedeing duration to 6 months: A literature review. Woman and Birth, 23(4), 135-145. http://dx.doi.org/10.1016/j.wombi.2 010.02.002.

Shams, B., Golshiri, P., Saleki, A., Isfagani, M. R., \& Najimi, A. (2012). Comparasion of growth and nutritional evolution stages in infants with working mothers and infants with housewife mothers in isfahan. Journal of Education and Health Promotion, 1(16). http://dx.doi.org/10.4103/22779631.98574.

Shor, E., Roelfs, D. J., \& Yogev, T. (2013). The strength of family ties: A meta-analysis and metaregression of self-reported social support an mortality. Journal of Social Network, 35, 626-638. http://dx.doi.org/10.1016/j.socnet.2 013.08 .004 
Siregar, M. (2007). Keterlibatan ibu bekerja dalam perkembangan pendidikan anak. Jurnal Harmoni Sosial,11(1), 8-18.

Sugiyono. (2011). Statistika untuk penelitian. Bandung: Alfabeta.

Susin, L. R. O., Giugliani, E. R. J., \& Kummer, S. C. (2005). Influence of grandmothers on breastfeeding practices. Rev Saúde Pública. 39 (2), 141-147.

Uchino, B. N. (2009). Understanding the links between social support and physical health, A life-span with emphasis on separability of perceived and received support. Perspective on Psychological Science. 4(3), 236-255.
Weingarden, H., \& Renshaw, K. (2014). Associations of obsessive compulsive symptoms and beliefs with depression: Testing mediation by shame and guilt. International Journal of Cognitive Therapy, 7(4), 1-15. http://dx.doi.org/10.1521/ ijct_2014_07_01.

Williams, P. (2005). What is social support? A grounded theory of social interaction in the context of the new family. Thesis. Department of Public Health University Adelaide. Diakses melalui https://digital.library. adelaide.edu.au/. 